\title{
Nicorandil alleviated cardiac hypoxia/reoxygenation-induced cytotoxicity via upregulating ketone body metabolism and ACAT1 activity
}

\author{
Yan Ping Bai ${ }^{1}$ and Lei Sen $\mathrm{Han}^{2, *}$ \\ 'Department of Cardiology, The Affiliated Hospital of Yan'an University, Yan'an 716000, ${ }^{2}$ Department of Cardiology, The Forth Renmin Hospital of Xi'an, Shanxi \\ Province 710004, China
}

\section{ARTICLE INFO}

Received January 28, 2018

Revised May 2, 2018

Accepted May 23, 2018

*Correspondence

Lei Sen Han

E-mail: hanleisen196601@126.com

\section{Key Words}

Acetyl-CoA acetyltransferase

Hypoxia reoxygenation

Ketone body

Nicorandil

OXCT1
ABSTRACT To study the effect of nicorandil pretreatment on ketone body metabolism and Acetyl-CoA acetyltransferase (ACAT1) activity in hypoxia/reoxygenation (H/ R)-induced cardiomyocytes. In our study, we applied H9c2 cardiomyocytes cell line to evaluate the cardioprotective effects of nicorandil. We detected mitochondrial viability, cellular apoptosis, reactive oxygen species (ROS) production and calcium overloading in $\mathrm{H} 9 \mathrm{c} 2$ cells that exposed to $\mathrm{H} / \mathrm{R}$-induced cytotoxicity. Then we evaluated whether nicorandil possibly regulated ketone body, mainly $\beta$-hydroxybutyrate (BHB) and acetoacetate (ACAC), metabolism by regulating ACAT1 and Succinyl-CoA:3-ketoacid coenzyme A transferase 1 (OXCT1) protein and gene expressions. Nicorandil protected $\mathrm{H} 9 \mathrm{c} 2$ cardiomyocytes against H/R-induced cytotoxicity dose-dependently by mitochondria-mediated anti-apoptosis pathway. Nicorandil significantly decreased cellular apoptotic rate and enhanced the ratio of $\mathrm{Bcl}-2 / \mathrm{Bax}$ expressions. Further, nicorandil decreased the production of ROS and alleviated calcium overloading in H/R-induced H9c2 cells. In crucial, nicorandil upregulated ACAT1 and OXCT1 protein expressions and either of their gene expressions, contributing to increased production of cellular BHB and ACAC. Nicorandil alleviated cardiomyocytes H/R-induced cytotoxicity through upregulating ACAT1/OXCT1 activity and ketone body metabolism, which might be a potential mechanism for emerging study of nicorandil and other $\mathrm{K}_{\text {ATP }}$ channel openers.

\section{INTRODUCTION}

Ischemia/reperfusion injury (IRI) caused myocardial detrimental damage by following blood restoration after coronary occlusion [1]. The most crucial inducers were calcium overloading and excessive ROS produced by mitochondria whose oxidative phosphorylation lost its normal function after reperfusion [2]. One of the clinical/experimental interventions was ischemic preconditioning (IPC) which targeted to mitochondrial ATPsensitive potassium channel $\left(\mathrm{K}_{\mathrm{ATP}}\right.$ channel), having been found could reduce the infarct size of heart left ventricular exposed to
(IRI) [3]. Mechanism study had uncovered that selectively activating $\mathrm{K}_{\mathrm{ATP}}$ channel by pharmacological intervention displayed the approximately effects of IPC in alleviating IRI [4]. Although IPC decreased ROS production after IRI, heart was an energyconsumption organ that demanded other energy metabolism for sufficient power supplying.

Ketone body was considered as a significant contributor to cellular and organic energy metabolism in biological states. Especially in pathological condition, ketone body acted as an important energetic source in mammalians when oxidative phosphorylation was damaged. Ketone body, consisted with 3-hydroxybutyrate of the Creative Commons Attribution Non-Commercial License, which permits unrestricted non-commercial use, distribution, and reproduction in any medium, provided the original work is properly cited. Copyright @ Korean J Physiol Pharmacol, pISSN 1226-4512, elSSN 2093-3827
Author contributions: L.S.H. performed the cell-based assay, mitochondrial viability assay, apoptosis, ROS and calcium measurement. Y.P.B. performed cell model of $\mathrm{H} / \mathrm{R}$, cellular protein and RNA measurement. L.S.H. supervised and wrote the manuscript. 
(BHB), acetoacetate (ACAC) and acetone, were produced in liver and diffused to bloodstream [5]. Insight into cardiomyopathy, reduction of ketone body oxidation had been found and promoted pathological progress while injection of $\mathrm{BHB}$ before ischemia displayed a cardioprotective effect which conferred to reduce the infarct size and cell death $[5,6]$. In aspect of I/R injury, an increased uptake of ketone body was found in cerebral as stress-induced energy substrate, but just sustained for several minutes [7]. That indicated in the early on-set of I/R injury, short-term upregulation of ketone body metabolism served as energy supplementary. However, it was not enough for maintaining in the long-last period of I/R injury. Whether extra-providing ketone body enabled to preserve cardiac function when experienced I/R injury or other cardiomyopathies.

Studies of Parkinson's diseases showed BHB exhibited neuroprotective effects via mitochondrial respiratory and ATP production improvement [8]. Moreover, BHB was served as an endogenous and specific inhibitor of histone deacetylases that increased Foxo3a and Mt2 promotor histone acetylation, contributing to protection against oxidative stress [9]. In aspect of heart failure, BHB acted as not only an energy carrier but also a signaling regulator in cardiac pathological progress. Treatment of $\mathrm{BHB}$ apparently attenuated ROS production and cellular apoptosis in response to $\mathrm{H}_{2} \mathrm{O}_{2}$-induced oxidative stress [10]. ACAC, $3 \mathrm{mM}$, has also been served as a neuroprotective agent to retinal ganglion cells (RGC) against neurodegeneration induced by NMDA [11] and protects hippocampal neurons against glutamate-induced toxicity by energy metabolism-related machenisms [12]. In addition, SCOT-Heart-KO mice displayed more susceptible to myocardial pressure and oxidative stress, suggesting an essential role of SCOT-mediated ketone body signaling in cellular energy metabolism [13].

Nicorandil, a $\mathrm{K}_{\text {ATP }}$ channel opener, had been demonstrated exhibiting good cardioprotective effects, including reducing infarct size, improving the recovery of myocardial contractile function and preventing oxidative stress-induced cellular apoptosis $[14,15]$. In addition, previous study had shown nicorandil attenuated IRI through PI3K/Akt signaling pathway to inhibit ER-stress-induced apoptosis [16]. However, whether nicorandil displayed the cardioprotective effects through the ketone body metabolism in H/Rinduced cardiomyocytes was rarely studied.

In our study, we performed in vitro models to evaluate the effects of nicorandil on H/R-induced cytotoxicity. Nicorandil increased cellular and mitochondrial viability in $\mathrm{H} 9 \mathrm{c} 2$ cells exposed to H/R. Meantime, nicorandil decreased ROS production, alleviated calcium overloading and reduced cellular apoptosis in mitochondria-mediated proapoptotic pathway. In crucial, nicorandil pretreatment upregulated protein and gene expressions of ACAT1 and OXCT1, and either of ketone body metabolism, which promisingly characterized the potential activities of $\mathrm{K}_{\mathrm{ATP}}$ channel openers on ketone body metabolism.

\section{METHODS}

\section{Cell culture}

Rat H9c2 cardiomyocyte cell line was purchased from the American Type Culture Collection (CRL1446, ATCC, USA). H9c2 cells were cultured in high glucose (4,500 mg/l) Dulbecco's Modified Eagle Medium (DMEM) composed of $10 \%$ fetal bovine serum (FBS) and 1\% v/v $100 \mathrm{U} / \mathrm{ml}$ penicillin and streptomycin (Gibco, Oklahoma, USA) in a humidified incubator containing 5\% $\mathrm{CO}_{2}$ at $37^{\circ} \mathrm{C}$.

\section{Pharmacological interventions}

For cellular treatment, nicorandil (Sigma-Aldrich, St. Louis, MO, USA) pretreated for $24 \mathrm{~h}$ and $\mathrm{H} / \mathrm{R}$ were performed when cells reached $80-90 \%$ confluency. $\mathrm{H} 9 \mathrm{c} 2$ cells were divided into 5 groups: i) control, cultured in normoxia $\left(20 \% \mathrm{O}_{2}, 5 \% \mathrm{CO}_{2}\right)$; ii) $\mathrm{H} / \mathrm{R}$ alone; iii) $\mathrm{H} / \mathrm{R}+$ nicorandil $(25 \mu \mathrm{M})$; iv) $\mathrm{H} / \mathrm{R}+$ nicorandil (50 $\mu \mathrm{M})$; and v) $\mathrm{H} / \mathrm{R}+$ nicorandil $(100 \mu \mathrm{M})$.

\section{In vitro model of $\mathrm{H} / \mathrm{R}$}

Hypoxia in H9c2 cells was induced by replacing the normoxia medium with Krebs-Ringer Bicarbonate (KRB) buffer that consisted of $115 \mathrm{mM} \mathrm{NaCl}, 4.7 \mathrm{mM} \mathrm{KCl}, 2.5 \mathrm{mM} \mathrm{CaCl}_{2}, 24 \mathrm{mM}$ $\mathrm{NaHCO}_{3}, 1.2 \mathrm{mM} \mathrm{KH}_{2} \mathrm{PO}_{4}, 1.2 \mathrm{mM} \mathrm{MgSO}, 10 \mathrm{mM}$ Hepes and $0.01 \% \mathrm{BSA}$, and placing cells into a chemical hypoxia system (BD, USA) that consumed oxygen rapidly to induce hypoxic condition. After $4 \mathrm{~h}$ hypoxia, H9c2 cells were subjected to reoxygenation by replacing the KRB buffer with cultural medium for $12 \mathrm{~h}$.

\section{Cell viability}

Cell viability of $\mathrm{H} 9 \mathrm{c} 2$ cells was determined by measuring the absorbance of 3-(4,5-dimethylthiazol-2-yl)-2,5-diphe-nyltetrazolium bromide (MTT) purchased from Sigma-Aldrich (St. Louis, MO, USA). Cells were seeded in 96-well microplates at a density of $1 \times 10^{4}$ cells per well. After pharmacological treatment, cells were exposed to $\mathrm{H} / \mathrm{R}$ and $100 \mu \mathrm{l}$ cultural medium containing MTT ( $5 \mathrm{mg} / \mathrm{ml}$, Invitrogen, USA) at a final concentration of 500 $\mu \mathrm{g} / \mathrm{ml}$ in PBS was added to the plates $(10 \mu \mathrm{l} /$ well $)$ and incubated for an additional $4 \mathrm{~h}$ at $37^{\circ} \mathrm{C}$. Then MTT solution was discarded and DMSO $(150 \mu \mathrm{l})$ was added to each well to solu-bilize formazan crystals formed in viable cells. The absorbance was measure optical density at 570/650 nm on a Multi-Mode Detection Platform (SpectraMax Paradigm, Molecular Devices, USA). Cell viability of control group was considered as $100 \%$.

\section{Mitochondrial viability}

H9c2 cells were seeded in the dark 96-well microplate at a den- 
sity of $1 \times 10^{4}$ cells per well. Cells were treated as described above. After treatments, the mitochondrial viability was evaluated by the mitochondrial viability assay kit (ab129732, Abcam, USA). The fluorescence was detected at $590 \mathrm{~nm}$ with an excitation wavelength of $550 \mathrm{~nm}$. Mitochondrial viability of control group was considered as $100 \%$.

\section{Apoptosis measurement}

H9c2 were seeded in 6-well plates $\left(2 \times 10^{6}\right.$ cells per well). Cells in the different treatment groups were harvested and resuspended in PBS. Following centrifugation at $1,000 \times \mathrm{g}$ for $5 \mathrm{~min}$, detached cells were collected and incubated with Annexin V-Fluorescein isothiocyanate (FITC) coupled with Annexin V protein and propidium iodide (PI) (Sigma-Aldrich, St. Louis, MO, USA) at room temperature in the dark for $15 \mathrm{~min}$. Immediately after gently pipetting, samples were analyzed by flow cytometry by performing with a 488-nm laser coupled to a cell sorter. Apoptotic cells were characterized by high Annexin V binding and high PI staining.

\section{ROS and calcium measurement}

Mitochondrial ROS was measured by the DCFDA Cellular ROS Detection Assay Kit (Invitrogen, USA) according to the commercial protocol. Cellular calcium overloading was measured by Fluo-4, AM (Invitrogen, USA) fluorescent probe staining according to commercial protocol. After H/R, cells were washed with PBS 1 time and digested by Trypsin-EDTA. Resuspended cells with cultural medium and incubated with DCFDA or Fluo4 probe for $30 \mathrm{~min}$ at $37^{\circ} \mathrm{C}$ in dark. The ROS production and calcium concentration in each group were detected using BD FACSAria III flow cytometer (BD, USA) by intensity of green fluorescence (Ex $488 \mathrm{~nm} / \mathrm{Em} 535 \mathrm{~nm}$ ).

\section{Western blot}

$\mathrm{H} 9 \mathrm{c} 2$ cells were lysed in ice-cold RIPA buffer (20 mM Tris- $\mathrm{HCl}$ (pH 7.5), 150 mM NaCl, 1 mM Na 2 EDTA, 1 mM EGTA, 1\% NP$40,1 \%$ sodium deoxycholate, $2.5 \mathrm{mM}$ sodium pyrophosphate, 1 $\mathrm{mM}$ beta-glycerophosphate, $1 \mathrm{mM} \mathrm{Na} \mathrm{VO}_{4}, 1 \mu \mathrm{g} / \mathrm{ml}$ leupeptin, Cell Signaling Technology, USA) with and proteinase inhibitor cocktail (Roche, Basel, Switzerland). The cell lysates were immediately centrifuged at $13,000 \mathrm{~g}$ for $15 \mathrm{~min}$ at $4^{\circ} \mathrm{C}$ and the supernatants were boiled with loading buffer for $10 \mathrm{~min}$. The concentrations of total proteins were quantified by the Bio-Rad protein assay kit (Bradford method) (Bio-Rad, CA, USA). Equal amounts of proteins (30 $\mu \mathrm{g} / \mathrm{lane}$ ) were separated by $10 \%$ SDSPAGE gels and transferred to NC membranes (pore size: $0.45 \mu \mathrm{m}$, Pall, BioTrace). The membranes were blocked in 5\% non-fat milk in TBST (Tris-buffer saline with 0.05\% Tween 20) for $1 \mathrm{~h}$ and incubated with ACAT1 (1:1000, Abcam, UK), OXCT1 (1:1000, Santa Cruz, USA), Bax and Bcl-2 (1:1000, Cell Signaling Technology, USA) primary antibodies overnight at $4^{\circ} \mathrm{C}$. $\beta$-Actin (Santa Cruz, USA) was used as the loading control. This process was followed by 3 times TBST washes for $15 \mathrm{~min}$ and incubation with the secondary fluorescent antibodies (1:5000, Odyssey, USA) for $2 \mathrm{~h}$ at room temperature in dark. The fluorescent signals of bands were detected by the Odyssey infrared imaging system (Belfast, USA). The densities of bands were normalized to Actin.

\section{RNA extraction, reverse transcription, and quantitative real-time PCR}

Total RNA was obtained from the cultured H9c2 cells using FavorPrep $^{\mathrm{TM}}$ Total RNA purification mini kit (Favorgen Biotech Corp., Pingtung, Taiwan). Tissues were lysed and homogenized in $300 \mu$ of lysis buffer (RLT Buffer; Qiagen, Basel, Switzerland), using the Fast Prep 24 lyzer (MPbio, Lucerne, Switzerland). Total RNA of tissue was isolated on spin columns with silica-based membranes (RNeasy Mini Kit; Qiagen), following the manufacturer's instructions. RNA was eluted with $30 \mu \mathrm{l}$ of $\mathrm{H}_{2} \mathrm{O}$. A small amount of purified RNA $(1 \mu \mathrm{g})$ from cells was reverse transcribed in a volume of $20 \mu \mathrm{l}$ using the RT High-Capacity RNA-to-cDNA Kit (Applied Biosystems, Rotkreuz, Switzerland). Synthesized cDNA was then stored at $-20^{\circ} \mathrm{C}$. Quantitative real-time PCR were performed with the $\mathrm{ViiA}^{\mathrm{TM}} 7$ real-time PCR system (Applied Biosytems, Grand Island, NY, USA) using the Taq polymerase master mix FastStart Universal SYBR-Green Master Rox (Roche Diagnostics, Indianapolis, IN, USA) according to the manufacturer's instructions. Primer sequences quantified for mRNA were directed against ACAT1, OXCT1, as well as $\beta$-actin mRNA used as an endogenous control (primer sequences are listed in Table 1). The PCR mixture is comprised of $10 \mu \mathrm{l}$ SYBR master mix, $0.5 \mu \mathrm{l}$ forward primers, $0.5 \mu \mathrm{l}$ reverse primers, $1 \mu \mathrm{g}$ template and $\mathrm{dd}_{2} \mathrm{O}$ makes up to $20 \mu \mathrm{l}$. The procedure of RCR is $50^{\circ} \mathrm{C}$ for 2 $\min , 95^{\circ} \mathrm{C}$ for $10 \mathrm{~min}$, followed by 45 cycles of $95^{\circ} \mathrm{C}$ for $15 \mathrm{~s}, 60^{\circ} \mathrm{C}$ for $60 \mathrm{~s}$. Gene expression level was based on the comparative CT value using the $2^{-\triangle \triangle \mathrm{CT}}$ method and normalized with $\beta$-actin.

Table1. Primer sequences

\begin{tabular}{cll}
\hline Name & \multicolumn{1}{c}{ Forward } & \multicolumn{1}{c}{ Reverse } \\
\hline ACAT1 & 5'-ATGGCTGCCCTGGCGGTTCTA-3' & $5^{\prime}$-CTACAGCTTCTCAATCAGCAC-3' \\
OXCT1 & 5'-CTGGAGTTTGAGGACGGCAT-3' & $5^{\prime}$-TCCGCATCAGCTTCGTCTTT-3' $^{\prime}$ \\
3-Actin & 5'-GCTACAGCTTCACCACCACA-3' & $5^{\prime}$-ATCGTACTCCTGCTTGCTGA-3' \\
\hline
\end{tabular}




\section{Cellular BHB and ACAC determination}

Cellular BHB concentrations were determined using a Colorimetric Assay Kit (Cayman Chemical Company, USA). The Cells $\left(\sim 18 \times 10^{6}\right.$ cells $)$ were collected with a rubber policeman and then centrifugated at $2,000 \mathrm{~g}$ for $10 \mathrm{~min}, 4^{\circ} \mathrm{C}$. Cell pellets were resuspended in 1-2 $\mathrm{ml}$ of cold assay buffer, then sonicated with $20 \times$ at $1 \mathrm{~s}$ bursts and centrifugated at $10,000 \mathrm{~g}$ for $10 \mathrm{~min}, 4^{\circ} \mathrm{C}$. Supernatants were removed, the pellets were resuspended in $1 \mathrm{ml}$ of cold assay buffer and stored on ice. Each sample was measured in triplicate with $50 \mu \mathrm{l}$ of the sample in each well, and reacted by adding $50 \mu \mathrm{l}$ of the developer solution. Then incubated the plate at $25^{\circ} \mathrm{C}$ in the dark for $30 \mathrm{~min}$ and then read the absorbance at 445-455 nm using a microplate reader.

Cellular ACAC concentrations were determined using a Colorimetric Assay Kit (Abcam, UK). After different treatments, cell pellets were collected and resuspended with $\mathrm{ddH}_{2} \mathrm{O}$. Sample volumes were adjusted to $110 \mu \mathrm{l}, 80 \mu \mathrm{l}$ ACAC assay buffer and 10 $\mu \mathrm{l}$ ACAC substrate were added and mixed well. After incubation at $25^{\circ} \mathrm{C}$ for $15 \mathrm{~min}$, the values of absorbance at OD $550 \mathrm{~nm}$ were measured in a kinetic mode.

\section{Cellular succinate and acetyl-CoA determination}

Cellular succinate concentrations were determined using a Colorimetric Assay Kit (BioVision, USA). In brief, H9c2 cells were homogenized rapidly and centrifuge at $10,000 \times \mathrm{g}$ for $5 \mathrm{~min}$. Collected the supernatants and mixed with reagents into 96-well plate. After $30 \mathrm{~min}$ incubation at $37^{\circ} \mathrm{C}$, samples were measured at $450 \mathrm{~nm}$. The values of control group were considered as 1.0.

Cellular ACAC concentrations were determined using a Colorimetric Assay Kit (Abnova, TaiWan) according to manufactory's protocol. H9c2 cells were homogenized rapidly on ice and centrifuge at $10,000 \times \mathrm{g}$. Supernatants were collected and neutralized $\mathrm{pH}$ to 6-8 and diluted volume to $50 \mu \mathrm{l}$. Then mixed samples with 50 $\mu \mathrm{l}$ reaction mix to be tested with fluorescent detection by using $E x / E m=535 / 589$. The values of control group were considered as 1.0 .

A

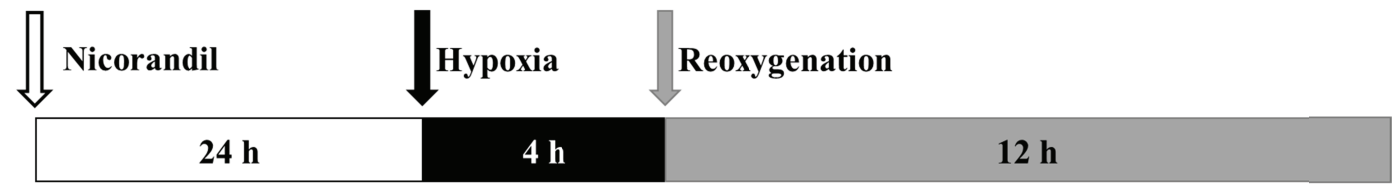

B

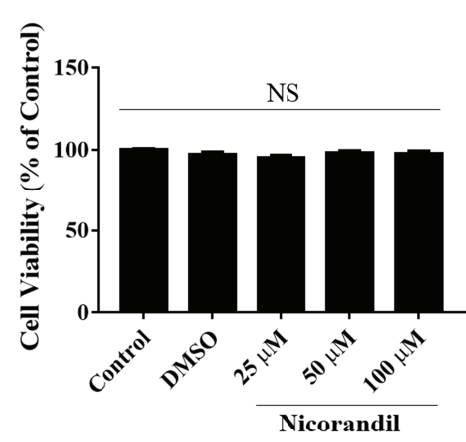

D

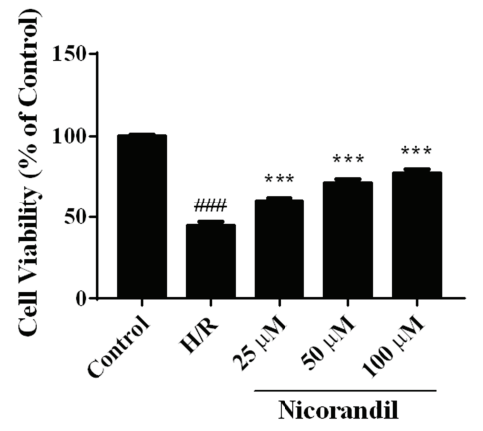

C

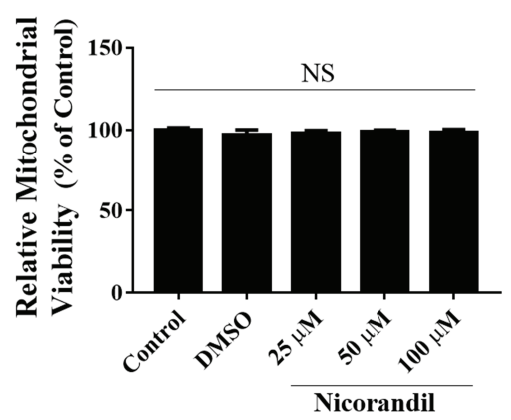

$\mathbf{E}$

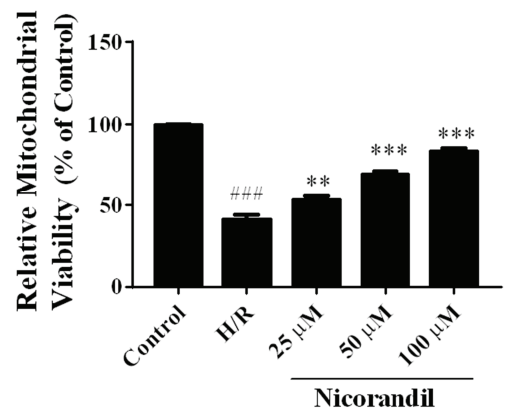

Fig. 1. Effects of nicorandil on cell and mitochondrial viability in H/R-induced H9c2 cells. (A) Hypoxia/reoxygenation protocol and drug treatment. Nicorandil was pretreatment $24 \mathrm{~h}$ before $\mathrm{H} / \mathrm{R}$. $\mathrm{H} / \mathrm{R}$ was induced by incubating cells in KRB buffer as hypoxia for $4 \mathrm{~h}$ followed by incubating cells in cultural medium as reoxygenation for $12 \mathrm{~h}$. (B, D) Effects of Nicorandil $(25,50,100 \mu \mathrm{M})$ on cell viability under normoxia or hypoxia conditioning determined by MTT assay. Data ( $n=3)$ were shown as the mean \pm SEM, NS: no significance. (C, E) Effects of nicorandil $(25,50,100 \mu M)$ on mitochondrial

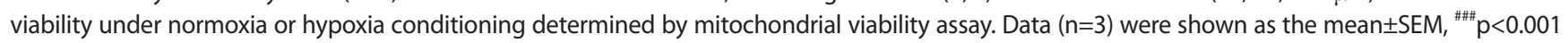
vs. control group, ${ }^{* *} \mathrm{p}<0.01$ vs. H/R group, ${ }^{* * *} \mathrm{p}<0.001$ vs. H/R group. 


\section{Statistics}

Data were analyzed by using GraphPad Prism 5.0, all data were expressed as the means \pm SEM. Student's t-test was used to analyze difference between 2 groups. Statistical significance was accepted as $\mathrm{p}<0.05$.

\section{RESULTS}

\section{Nicorandil protected cardiomyocytes against $H / R$ -induced cytotoxicity}

To examine whether nicorandil had anti-H/R effect, we used a well-established H/R model that consisted of $4 \mathrm{~h}$ hypoxia followed by $12 \mathrm{~h}$ reoxygenation as shown in Fig. 1A. At first, MTT assays and mitochondrial viability assay were performed to evaluate cytotoxicity of nicorandil, and the control was used as a maximum reference (100\%) to calculate the effects of nicorandil $(25,50,100 \mu \mathrm{M})$ on cell and mitochondrial viability. After $24 \mathrm{~h}$ treatment, increasing concentrations of nicorandil (up to $100 \mu \mathrm{M}$ ) did not cause cellular cytotoxicity in $\mathrm{H} 9 \mathrm{c} 2$ cells as shown in Fig. 1B. Consistently, different concentrations of nicorandil showed no significant effect on mitochondrial viability (Fig. 1C).

Subsequently, H/R significantly decreased the cell and mitochondrial viability over $50 \%$ compared with control group (100\%), respectively. Increasing concentrations of nicorandil treatment enhanced cardiomyocytes survival after $\mathrm{H} / \mathrm{R}$ in a dose-dependent

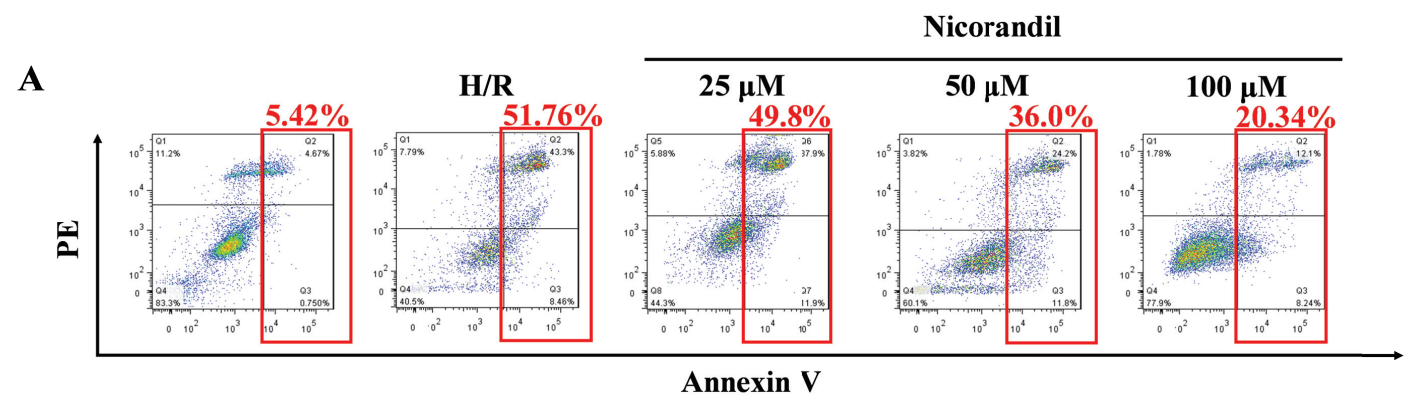

B

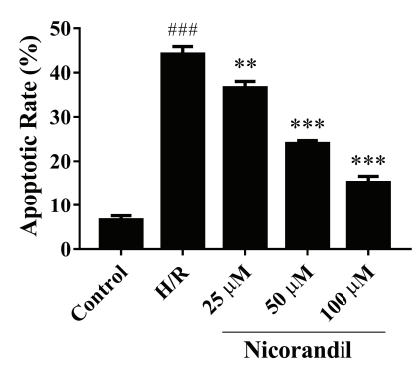

$\mathbf{E}$

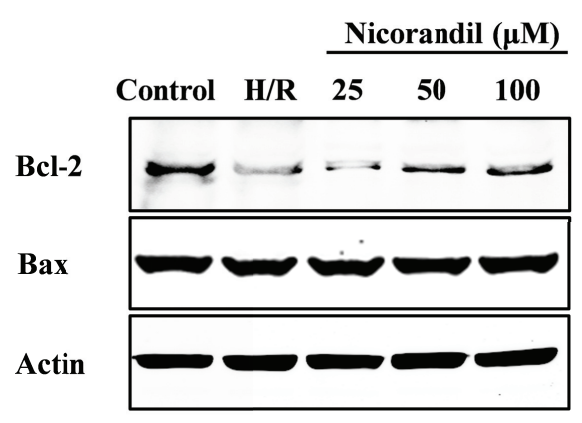

D

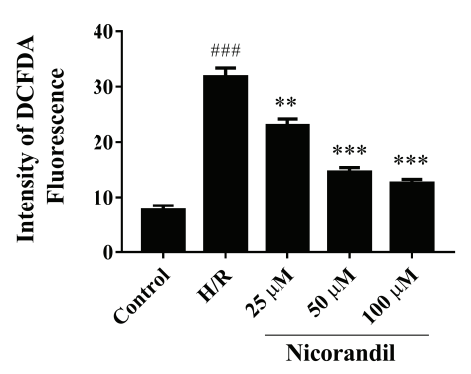

F

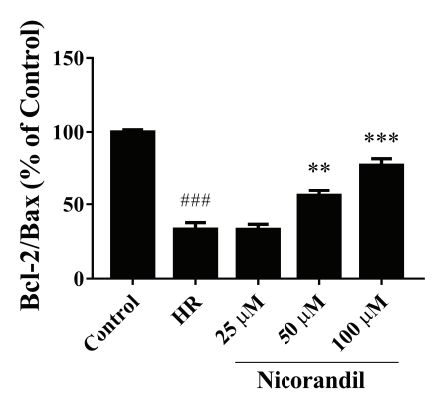

Fig. 2. Effects of nicorandil on cellular apoptosis, ROS production and calcium overloading in H/R-induced H9c2 cells. (A, B) Effects of nicorandil $(25,50,100 \mu \mathrm{M})$ on cellular apoptosis was detected by PI and Annexin V double staining evaluated by flow cytometry. Data $(n=3)$ were presented as mean \pm SEM. ${ }^{\# \#} \mathrm{p}<0.001$ vs. control group, ${ }^{* *} \mathrm{p}<0.01 \mathrm{vs.} \mathrm{H} / \mathrm{R}$ group, ${ }^{* *} \mathrm{p}<0.001 \mathrm{vs}$. $\mathrm{H} / \mathrm{R}$ group. (C) ROS production was detected by $\mathrm{H}_{2} \mathrm{DCFDA}$ probe staining and evaluated by flow cytometry. Data $(n=3)$ were presented as mean $\pm S E M$. ${ }^{\# \#} p<0.001$ vs. control group, ${ }^{* *} p<0.01$ vs. H/R group, ${ }^{* * *} p<0.001$ vs. H/R group. (D) Calcium concentration was detected by Fluo-4 AM staining and evaluated by flow cytometry. Data ( $\left.n=3\right)$ were presented as mean \pm SEM. ${ }^{\# \#} p<0.001$ vs. control group, ${ }^{*} p<0.05$ vs. H/R group, ${ }^{* * *} p<0.001$ vs. H/R group. (E, F) The expression of $B c l-2$ and $B a x$ were detected by western blotting. $\beta$-Actin as a loading control. Data $(n=3)$ were presented as mean $\pm S E M$. ${ }^{\# \# \#} p<0.001$ vs. control group, ${ }^{*} p<0.05$ vs. H/R group, ${ }^{* * *} \mathrm{p}<0.001$ vs. $\mathrm{H} / \mathrm{R}$ group. 
manner, showing a maximum of $77 \%$ cell viability and $78 \%$ mitochondrial viability with $100 \mu \mathrm{M}$ nicorandil (Figs. 1D and E).

\section{Nicorandil suppressed cellular apoptosis and oxidative stress in $\mathrm{H} 9 \mathrm{c} 2$ cells exposed to $\mathrm{H} / \mathrm{R}$}

Quantitative analysis using flow cytometry further confirmed that the apoptotic index (percentage of cells in early apoptosis plus late apoptosis) was markedly increased in H/R group (more than $40 \%$ ) compared with that of control group (less than 10\%). However, a decrease in the apoptotic rate was observed in $\mathrm{H} 9 \mathrm{c} 2$ cells pretreated with nicorandil (Figs. 2A and B). The effect of nicorandil at the concentration of $100 \mu \mathrm{M}$ decreased apoptotic rate to less than $20 \%$.

Next, mitochondrial ROS was measured by the DCFDA fluorescent probes staining. H9c2 cells exposed to H/R resulted in significantly enhancement of ROS level compared with the control group. Treatment of nicorandil at the concentration of $25 \mu \mathrm{M}$ significantly suppressed ROS level, and nicorandil at the concentration of $100 \mu \mathrm{M}$ abolished H/R-induced ROS generation in large extent (Fig. 2C). Moreover, investigation was employed to determine whether the cardioprotective effect of nicorandil was related to the suppression of intracellular calcium overloading after H/R. Fig. 2D showed a significant decrease of calcium concentration in nicorandil groups compared with $\mathrm{H} / \mathrm{R}$ group.

To further explore the potential apoptotic signaling in protective effect of nicorandil against H/R-induced cytotoxicity, the expressions of Bax and Bcl-2 were measured by western blotting. As shown in Fig. 2E, compared with the normal group, the expres- sion of $\mathrm{Bcl}-2$ decreased in the $\mathrm{H} / \mathrm{R}$ group while the expression of Bax did not change, showing the decreased ratio of Bcl-2 to Bax in $\mathrm{H} / \mathrm{R}$ group. Pretreatment of nicorandil increased the protein expressions of Bcl-2 and the ratio of Bcl-2 to Bax dose-dependently, comparing with $\mathrm{H} / \mathrm{R}$ group (Figs. $2 \mathrm{E}$ and $\mathrm{F}$ ).

\section{Nicorandil up-regulated ACAT1 and OXCT1 expressions in $\mathrm{H} 9 \mathrm{c} 2$ cells exposed to $\mathrm{H} / \mathrm{R}$}

To demonstrate the potential of nicorandil on ketone body metabolism, we evaluated the expressions of ACAT1 and OXCT1 in H9c2 cells induced by H/R. Firstly, immunoblot analysis showed decreasing protein levels of ACAT1 and OXCT1 in H9c2 cells induced by H/R. Interestingly, nicorandil significantly increased the protein levels of ACAT1 and OXCT1 in dose-dependent manner (Figs. 3A and B). Then we further confirmed with the mRNA expression of ACAT1 and OXCT1. After H/R, ACAT1 and OXCT1 mRNA expressions were significantly decreased. Changes in these mRNA levels were consistent with the up-regulation of protein levels, nicorandil enhanced mRNA expressions of ACAT1 and OXCT1 with a great extent comparing with H/R group (Fig. 3C).

\section{Nicorandil up-regulated ketone body metabolism in H9c2 cells exposed to $H / R$}

In addition, we performed detection of $\mathrm{BHB}$ and $\mathrm{ACAC}$ concentration to examine the effects of nicorandil in H/R-induced $\mathrm{H} 9 \mathrm{c} 2$ cells. BHB concentration was decreased significantly in $\mathrm{H} /$

A

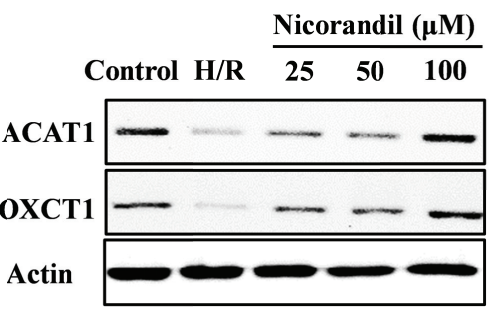

B
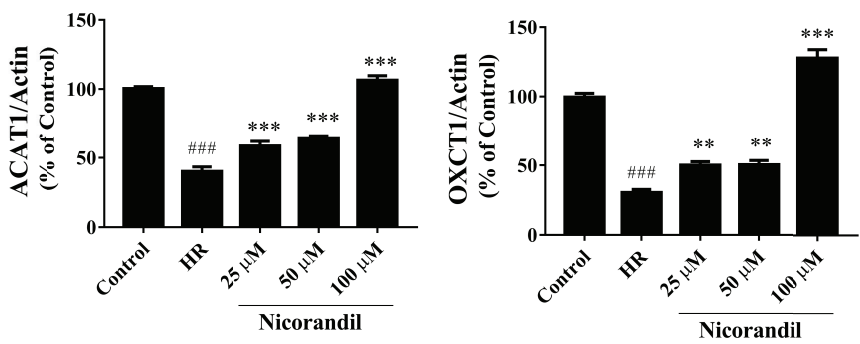

C
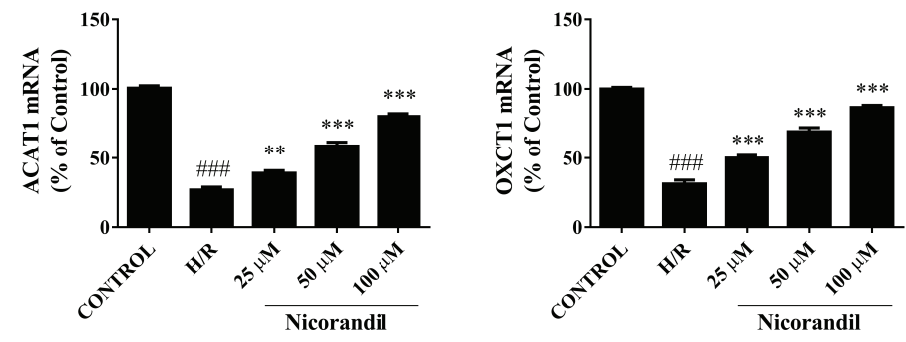

Fig. 3. The effects of nicorandil on ACAT1 and OXCT1 protein expressions in H/R-induced H9c2 cells. (A) The expression of ACAT1 and OXCT1 were detected by western blotting. $\beta$-Actin as a loading control. (B) The relative protein expressions were calculated by normalizing to $\beta$-Actin. Data $(n=3)$ were presented as mean \pm SEM. ${ }^{\# \#} p<0.001$ vs. control group, ${ }^{* *} p<0.01 \mathrm{vs.} \mathrm{H/R}$ group, ${ }^{* * *} p<0.001 \mathrm{vs}$. H/R group. (C) mRNA levels were quantified by real-time RT-PCR. Data $(n=3)$ were presented as mean \pm SEM. ${ }^{\# \# \#} p<0.001$ vs. control group, ${ }^{* *} p<0.01$ vs. H/R group, ${ }^{* * *} p<0.001$ vs. H/R group. 
A

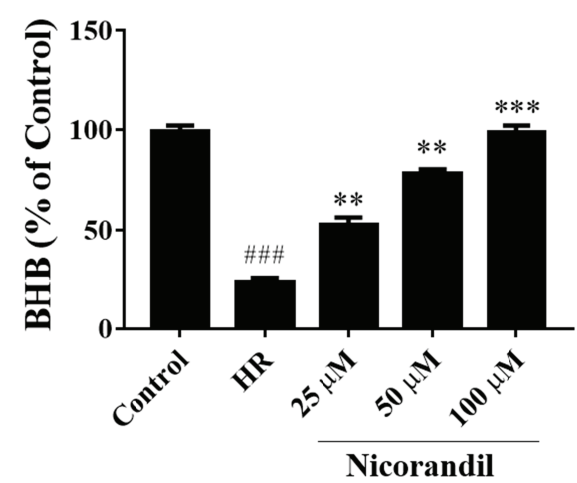

B

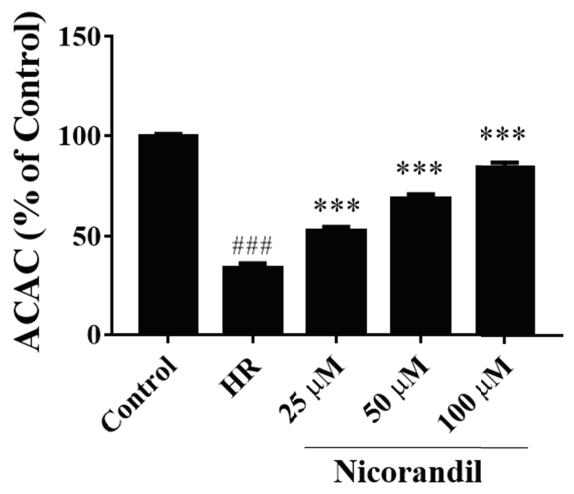

Fig. 4. Effects of nicorandil on ketone bodies productions in H/R-induced H9c2 cells. (A) The concentration of $\beta$-hydroxybutyrate (BHB) in cell extractions. Data $(n=3)$ were presented as mean \pm SEM. ${ }^{\# \# \#} p<0.001$ vs. control group, ${ }^{* *} p<0.01$ vs. $H / R$ group, ${ }^{* * *} p<0.001$ vs. H/R group. (B) The concentration of acetoacetate (ACAC) in cell extractions. Data $(n=3)$ were presented as mean $\pm S E M$. ${ }^{\# \#} p<0.001$ vs. control group, ${ }^{* * *} p<0.001$ vs. $H / R$ group.

A

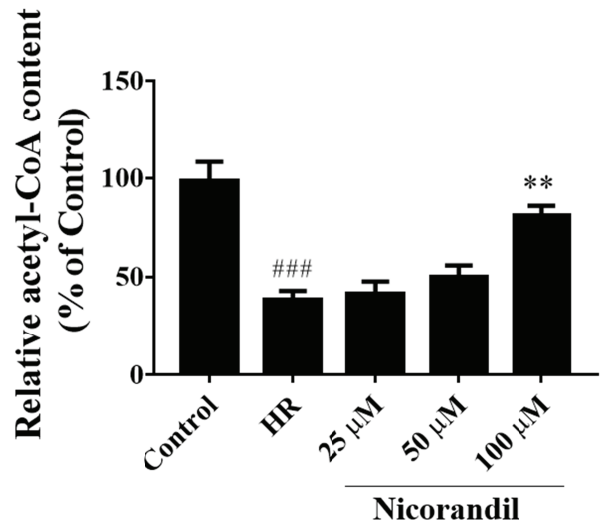

B

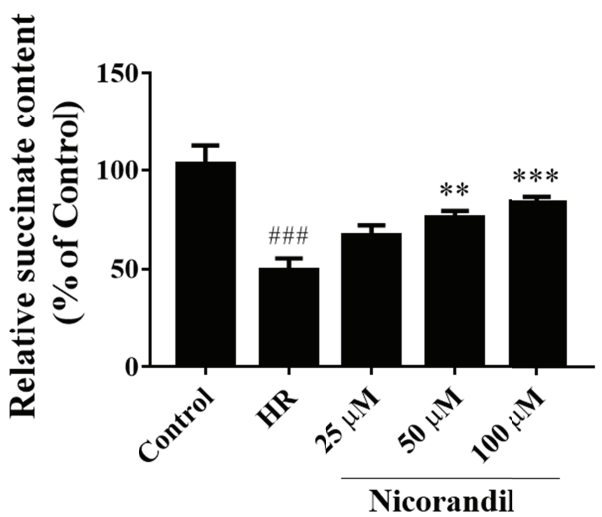

Fig. 5. Effects of nicorandil on productions of acetyl-CoA and succinate in H/R-induced H9c2 cells. (A) The concentration of acetyl-CoA in cell extractions. Data $(n=3)$ were presented as mean \pm SEM. ${ }^{* \# \#} p<0.001$ vs. control group, ${ }^{* *} p<0.01 \mathrm{vs.} \mathrm{H/R}$ group. (B) The concentration of succinate in cell extractions. Data $(n=3)$ were presented as mean \pm SEM. ${ }^{\# \#} p<0.001$ vs. control group, ${ }^{* *} p<0.01$ vs. H/R group, ${ }^{* * *} p<0.001$ vs. H/R group.

R group, and nicorandil up-reuglated $\mathrm{BHB}$ in $\mathrm{H} / \mathrm{R}$-induced $\mathrm{H} 9 \mathrm{c} 2$ cells (Fig. 4A). Meanwhile, ACAT level reduced significantly in $\mathrm{H} / \mathrm{R}$ group, followed by a significant augmentation in nicorandil group in dose-dependent manner (Fig. 4B). The combined analysis $(\mathrm{ACAC}+\mathrm{BHB})$ presented the similar decent when compared with the expressions of ACAT1 and OXCT1 that demonstrated a significant elevation of ketone body metabolism in nicorandil pretreated $\mathrm{H} 9 \mathrm{c} 2$ cells in expose to $\mathrm{H} / \mathrm{R}$.

\section{Nicorandil up-regulated succinate and acetyl-CoA production in $\mathrm{H} 9 \mathrm{c} 2$ cells exposed to $\mathrm{H} / \mathrm{R}$}

To further evaluate the activities of ACAT1 and SCOT1, we detected the concentrations of their metabolic products, succinate and acetyl-CoA. In cells exposed to H/R, the amounts of succinate and acetyl-CoA decreased significantly, while pretreatment of nicorandil significantly increased the amounts of succinate and
acetyl-CoA, suggesting the upregulated expressions of ACAT1 and SCOT1 contributed to enhanced ketone body metabolism (Figs. 5A and B).

\section{DISCUSSION}

Nicorandil had been demonstrated protected heart and brain against ischemia/reperfusion injury by reducing cell apoptosis. As nicorandil is a mitochondrial $\mathrm{K}_{\mathrm{ATP}}$ channel opener, it presents preconditioning effects and maintains energy metabolism when experiencing lethal injury. However, even if nicorandil could help mitochondria for their oxidative phosphorylation process, it was not enough for normal energy consumption, especially in reperfusion period, in which large amount of ROS produced and electron transport chain would be ineffective. Taking it for consideration, the reason why nicorandil can still display a good 
effect on I/R injury probably because of a supplementary energy metabolism system----ketone body metabolism. In our study, we used in vitro model of hypoxia/reoxygenation $(\mathrm{H} / \mathrm{R})$ in $\mathrm{H} 9 \mathrm{c} 2$ cell line to mimetic in vivo model of ischemia/reperfusion injury. After experiencing $4 \mathrm{~h}$ hypoxia and $24 \mathrm{~h}$ reoxygenation, H9c2 cell viability decreased more than $50 \%$, as well as mitochondrial viability, demonstrating it was applicable for the subsequent study. Pretreatment of nicorandil displayed cardioprotective effects evaluated by MTT assay and mitochondrial viability assay. To further evaluated whether nicorandil could reduce cellular apoptosis, we performed Annexin V/PI double staining assay to detected cellular apoptotic rate after $\mathrm{H} / \mathrm{R}$. Results analyzed by flow cytometry showed there was a significantly increasing population of apoptotic cells (over 40\%), comparing with control group (less than $10 \%)$. Pretreatment of nicorandil decreased cellular apoptotic rate dose-dependent (less than $20 \%$ in $100 \mu \mathrm{M}$ nicorandil treatment group). Taken together, our in vitro model of $\mathrm{H} / \mathrm{R}$ major caused H9c2 cells death by inducing cellular apoptosis and nicorandil reduced myocardial injury by increasing mitochondrial viability and preventing cellular apoptosis.

Oxidative stress and calcium overloading were considered as two main hypotheses to explain the pathogenetic progress of ischemia/reperfusion injury. In general, oxidative stress, associated with extra-formation of reactive oxygen species (ROS), contributed to modification of phospholipids and proteins and further changed membrane permeability. That influences membrane ion channels, like $\mathrm{Na}^{+} / \mathrm{K}^{+}$pump and $\mathrm{Ca}^{2+}$ pump, which impaired the balance of internal and external concentration of $\mathrm{Ca}^{2+}$, leading to calcium overloading [17]. Our in vitro model of H/R significantly increased cellular ROS production and caused calcium overloading in $\mathrm{H} 9 \mathrm{c} 2$ cells. Pretreatment of nicorandil had the ability to reduce the excessive production of ROS and calcium overloading dose-dependently, indicating nicorandil protected cardiomyocytes against $\mathrm{H} / \mathrm{R}$ by alleviating oxidative stress.

Beyond the theory that oxidative phosphorylation would lose its function for a long-term period even when oxygen was resupplied to cardiomyocytes [1], there was, doubtlessly, other energy production pathways to maintain cellular metabolism for cell survival. Whether improving these metabolisms' efficiency could address the issue of energy supplying to keep cell survival when experiencing H/R. One of energetic sources that feed cells in oxygen-existing condition is ketone body metabolism. Ketone bodies, served as supplementary energy source for energy-consumption tissues in times of fasting and exercise $[2,3]$, were produced by fatty acids via mitochondrial $\beta$-oxidation in liver. The fatty acids were firstly metabolized to acetyl-CoA and then produced to ACAC, which was the precursor of the other ketone bodies, acetone and $\mathrm{BHB}$. When taken up by heart, $\mathrm{BHB}$ will converted back into ACAC. Meantime, ACAC obtained a CoA donated by Succinyl-CoA to form acetoacetyl-CoA, catalyzed by OXCT1 (also known as SCOT). Then acetoacetyl-CoA were going to be converted to two acetyl-CoA by ACAT1 and participated into tricar- boxylic acid cycle for ATP production [18]. Take insight into cardiac pathogenesis, while the role of fatty acids had been explored decades, the dynamics of ketone body metabolism in regulation of myocardial energy utilization and mitochondrial biogenetics were rarely studied when facing external stresses. Rebecca C. Schugar's study demonstrated ketone body oxidation play an important role in free radical homeostasis that promoted myocardial response to pressure overloading [13]. In the failing heart, energy demand was considered as the most important problem as well as the cardiac capacity to utilize other fuels, such as ketone body. In Gregory Aubert's study, they used quantitative mitochondrial proteomics to identify dysfunctional proteins during the development of heart failing. They found proteins involved in ketone body metabolism were downregulated in failing heart. Moreover, they uncovered that ketone bodies oxidation reduced heart failing in an ex vivo model of isolated perfused heart, indicating they acted as a crucial fuel source for energy metabolism [19]. In extent of failing human heart, ketone body utilization performed as an alternative fuel and adaptive metabolic products [20]. In our study, the protein expressions of ACAT1 and OXCT1 decreased in H9c2 cells exposed to H/R. Pretreatment of nicorandil significantly upregulated the protein expressions of ACAT1 and OXCT1 and either of their mRNA expressions. Further quantification of ketone bodies showed nicorandil also upregulated two major metabolic products, BHB and ACAC. Moreover, pretreatment of nicorandil significantly increased the amounts of succinate and acetyl-CoA, suggesting the upregulated expressions of ACAT1 and SCOT1 contributed to enhanced ketone body metabolism.

Beyond basic acknowledgement between ketone body and energy metabolism, novel insights of ketone body functions were discovered. Recent study showed gut microbiota increased ketone utilization during fasting by using functional genomic, biochemical, and physiologic assays, implying the benefit provided by gut microbiota in myocardial ketone body metabolism [21]. Ketone body also suppressed autophagic elimination in neurons to prevent cell death induced by glucose deprivation. In the presence of BHB, the level of LC3-II and p62 declined in neurons in expose to glucose deprivation [22]. Our finding gives a new insight into the effect of nicorandil on cardiac injury and cellular apoptosis via regulation of ketone body metabolism, by which these results enrich our view to better understand the complex energy metabolisms in heart when experiencing I/R injury and new strategy for drug discovery.

\section{ACKNOWLEDGEMENTS}

This research was supported by the Clinical Study on Pharmacokinetics of Three Cephalosporins in Cerebrospinal Fluid Based on HPLC Fund 2017SF-257. 


\section{CONFLICTS OF INTEREST}

The authors declare no conflicts of interest.

\section{REFERENCES}

1. Yellon DM, Hausenloy DJ. Myocardial reperfusion injury. N Engl J Med. 2007;357:1121-1135.

2. Silachev DN, Plotnikov EY, Pevzner IB, Zorova LD, Babenko VA, Zorov SD, Popkov VA, Jankauskas SS, Zinchenko VP, Sukhikh GT, Zorov DB. The mitochondrion as a key regulator of ischaemic tolerance and injury. Heart Lung Circ. 2014;23:897-904.

3. Abete P, Testa G, Cacciatore F, Della-Morte D, Galizia G, Langellotto A, Rengo F. Ischemic preconditioning in the younger and aged heart. Aging Dis. 2011;2:138-148.

4. Kloner RA, Rezkalla SH. Preconditioning, postconditioning and their application to clinical cardiology. Cardiovasc Res. 2006;70:297307.

5. Fukao T, Mitchell G, Sass JO, Hori T, Orii K, Aoyama Y. Ketone body metabolism and its defects. J Inherit Metab Dis. 2014;37:541551.

6. Cotter DG, Schugar RC, Crawford PA. Ketone body metabolism and cardiovascular disease. Am J Physiol Heart Circ Physiol. 2013;304: H1060-H1076.

7. Faria MH, Muniz LR, Vasconcelos PR. Ketone bodies metabolism during ischemic and reperfusion brain injuries following bilateral occlusion of common carotid arteries in rats. Acta Cir Bras. 2007;22: 125-129.

8. Tieu K, Perier C, Caspersen C, Teismann P, Wu DC, Yan SD, Naini A, Vila M, Jackson-Lewis V, Ramasamy R, Przedborski S. D- $\beta$ hydroxybutyrate rescues mitochondrial respiration and mitigates features of Parkinson disease. JClin Invest. 2003;112:892-901.

9. Shimazu T, Hirschey MD, Newman J, He W, Shirakawa K, Le Moan N, Grueter CA, Lim H, Saunders LR, Stevens RD, Newgard CB, Farese RV Jr, de Cabo R, Ulrich S, Akassoglou K, Verdin E. Suppression of oxidative stress by $\beta$-hydroxybutyrate, an endogenous histone deacetylase inhibitor. Science. 2013;339:211-214.

10. Nagao M, Toh R, Irino Y, Mori T, Nakajima H, Hara T, Honjo T, Satomi-Kobayashi S, Shinke T, Tanaka H, Ishida T, Hirata K. $\beta$ Hydroxybutyrate elevation as a compensatory response against oxidative stress in cardiomyocytes. Biochem Biophys Res Commun. 2016;475:322-328.

11. Thaler S, Choragiewicz TJ, Rejdak R, Fiedorowicz M, Turski WA, Tulidowicz-Bielak M, Zrenner E, Schuettauf F, Zarnowski T. Neuro- protection by acetoacetate and $\beta$-hydroxybutyrate against NMDAinduced RGC damage in rat--possible involvement of kynurenic acid. Graefes Arch Clin Exp Ophthalmol. 2010;248:1729-1735.

12. Massieu L, Haces ML, Montiel T, Hernández-Fonseca K. Acetoacetate protects hippocampal neurons against glutamate-mediated neuronal damage during glycolysis inhibition. Neuroscience. 2003; 120:365-378.

13. Schugar RC, Moll AR, André d'Avignon D, Weinheimer CJ, Kovacs A, Crawford PA. Cardiomyocyte-specific deficiency of ketone body metabolism promotes accelerated pathological remodeling. Mol Metab. 2014;3:754-769.

14. Li W, Wu N, Shu W, Jia D, Jia P. Pharmacological preconditioning and postconditioning with nicorandil attenuates ischemia/reperfusion-induced myocardial necrosis and apoptosis in hypercholesterolemic rats. Exp Ther Med. 2015;10:2197-2205.

15. Ishii H, Ichimiya S, Kanashiro M, Amano T, Imai K, Murohara T, Matsubara T. Impact of a single intravenous administration of nicorandil before reperfusion in patients with ST-segment-elevation myocardial infarction. Circulation. 2005;112:1284-1288.

16. Wu H, Ye M, Yang J, Ding J, Yang J, Dong W, Wang X. Nicorandil protects the heart from ischemia/reperfusion injury by attenuating endoplasmic reticulum response-induced apoptosis through PI3K/ Akt signaling pathway. Cell Physiol Biochem. 2015;35:2320-2332.

17. Dhalla NS, Elmoselhi AB, Hata T, Makino N. Status of myocardial antioxidants in ischemia-reperfusion injury. Cardiovasc Res. 2000; 47:446-456

18. Newman JC, Verdin E. Ketone bodies as signaling metabolites. Trends Endocrinol Metab. 2014;25:42-52.

19. Aubert G, Martin OJ, Horton JL, Lai L, Vega RB, Leone TC, Koves T, Gardell SJ, Krüger M, Hoppel CL, Lewandowski ED, Crawford PA, Muoio DM, Kelly DP. The failing heart relies on ketone bodies as a fuel. Circulation. 2016;133:698-705.

20. Bedi KC Jr, Snyder NW, Brandimarto J, Aziz M, Mesaros C, Worth AJ, Wang LL, Javaheri A, Blair IA, Margulies KB, Rame JE. Evidence for intramyocardial disruption of lipid metabolism and increased myocardial ketone utilization in advanced human heart failure. Circulation. 2016;133:706-716.

21. Crawford PA, Crowley JR, Sambandam N, Muegge BD, Costello EK, Hamady M, Knight R, Gordon JI. Regulation of myocardial ketone body metabolism by the gut microbiota during nutrient deprivation. Proc Natl Acad Sci U S A. 2009;106:11276-11281.

22. Camberos-Luna L, Gerónimo-Olvera C, Montiel T, Rincon-Heredia $\mathrm{R}$, Massieu L. The ketone body, $\beta$-hydroxybutyrate stimulates the autophagic flux and prevents neuronal death induced by glucose deprivation in cortical cultured neurons. Neurochem Res. 2016;41: 600-609. 